\title{
CRÍTICA AO PENSAMENTO DE KAREL VASAK E NORBERTO BOBBIO ACERCA DO SURGIMENTO DOS DIREITOS HUMANOS EM FACE AOS TRATADOS E CONVENÇÕES INTERNACIONAIS*
}

\author{
CRÍTICA AL PENSAMIENTO DE KAREL \\ VASAK Y NORBERTO BOBBIO EN LA \\ APARICIÓN DE LOS DERECHOS HUMANOS \\ EN RELACIÓN CON LOS TRATADOS Y \\ CONVENCIONES INTERNACIONALES
}

\author{
CRITICAL TO THE THOUGHT OF KAREL \\ VASAK AND NORBERTO BOBBIO ON THE \\ DEVELOPMENT OF HUMAN RIGHTS IN \\ CONNECTION WITH INTERNATIONAL \\ TREATIES AND CONVENTIONS
}

Norton Maldonado Dias**

Data de recepção: 30 de setembro de 2016 Data de aceitação: 28 de abril de 2017 Disponibilidade em linha: 30 de novembro de 2017

* Através da metodologia dedutiva e bibliografica, o trabalho se desenvolveu na forma investigativa, fazendo alusão a uma critica a uma das mais repercutidas teorias acerca do processo de surgimento dos direitos humanos, formulada por Karel Vasak e Norberto Bobbio denominada "Geraçoes dos Direitos". O objetivo foi, justamente, investigar se os direitos humanos surgiam no momento em que eram positivados, porém a previsão positivista ocorrida nos Tratados Internacionais não seguiram a mesma cronologia proposta por Vasak e Bobbio, afastando o critério positivista formal para afirmar o surgimento de direitos.

** Professor da Faculdade de Direito de Sinop (Mato Grosso, Brasil) nas disciplinas de Direito Constitucional I e II, Teoria Geral do Direito Civil. No projeto Resolve Direito, que prepara acadêmicos desta instituição para os exames da $\mathrm{OAB}$ (Ordem dos Advogados do Brasil). Advogado (Mato Grosso e São Paulo, Brasil). Mestrado em Direito (Centro Universitário Eurípides de Marília, Brasil). Especialização em Direito na pós-graduação da UEL - Universidade Estadual de Londrina (Paraná, Brasil). Lecionou ainda nas disciplinas de Teoria da Iniciação Científica, Monografia I, Direito Ambiental e Criminologia). Atuação na pesquisa no grupo indexado ao Diretório do CNPQ: Gramática dos Direitos Fundamentais. Contato: maldonadodias@hotmail. com.br 


\section{Para citar este artigo / Para citar este artículo / To cite this article}

DIAS, Norton Maldonado, Crítica ao pensamento de Karel Vasake Norberto Bobbio acerca do surgimento dos direitos humanos em face aos tratados e convenções internacionais, 31 International Law, Revista Colombiana de Derecho Internacional, 59-80 (2016). https://doi.org/10.11144/ Javeriana.il 15-31.cpvb doi:10.11144/Javeriana.i115-31.cpvb

\section{RESUMO}

Otrabalhointitulado Aerados direitos, deautoria de Norberto Bobbio, consiste em uma das principais fontes que afirmam um primeiro momento de proteção no histórico do constitucionalismo que, na linha do pensamento de Karel Vasak, determinou o surgimento dos denominados direitos civis e políticos como prerrogativas de primeira geração ou dimensão. Porém, do ponto de vista de Tratados e Convenções Internacionais, as primeiras proteções não ocorreram com direitos civis e políticos como propôs o pensamento de Vasak e Bobbio, mas sim com os direitos sociais protegidos com a Convenção da OIT (Organização Internacional do Trabalho) de 1919. Assim, os desvios do pensamento das gerações e dimensões de direitos em detrimento as primeiras formalizações em Tratados e Convenções Internacionais acabam pontuando problemas que afirmam que o surgimento de direitos humanos não depende do momento em que foram juridicamente protegidos. $\mathrm{O}$ trabalho conclui que o surgimento de direitos consiste em processo multifatorial, reduzindo o critério positivista que atenta ao momento histórico de proteção jurídica de direitos como tão somente um dentre os vários fatores que devem influenciar o surgimento desses direitos. Em resumo, direitos surgem de inúmeros fatores, dentre os quais, de natureza antropológica, histórica, sociológicas, tecnológicas e outras; colocando o momento de proteção e formalização jurídicas de direitos, não como fator determinante, mas sim como uma das várias influências a serem consideradas no processo de surgimento e determinação de prerrogativas fundamentais.

Palavras-chave: Surgimento dos direitos humanos. Vasak. Bobbio

\section{RESUMEN}

El trabajo titulado La era de los derechos, escrito por Norberto Bobbio, es una de las principales fuentes que afirman uno primero tiempo de la protección en la historia del constitucionalismo que, en la línea del pensamiento de Karel Vasak, determina la aparición de los llamados derechos civiles y políticos como de primera generación o dimensión derechos. Sin embargo, desde el punto de vista de los tratados y convenciones internacionales, las primeras protecciones no se produjo con los derechos civiles y politicos como propuso la idea de Vasak 
y Bobbio, pero con los derechos sociales protegidos por la Convención de la OIT (Organización Internacional del Trabajo) 1919. Por lo tanto, las desviaciones de la idea de "generaciones" y "dimensiones" de los derechos sobre la primera formalización de los tratados y convenciones internacionales problemas de puntuación final que afirman que la aparición de los derechos humanos no depende de la época estaban protegidos legalmente. El documento concluye que la aparición de los derechos es un proceso multifactorial, reduciendo el criterio positivista que se parece al momento histórico de la protección legal de los derechos, como solo uno de varios factores que deben influir en la aparición de estos derechos. En resumen, surgen los derechos de muchos factores, entre los cuales, antropológicos, históricos, sociológicos, tecnológicos y otros; comprendiendo el tiempo para la protección y la formalización de los derechos legales, no como un factor determinante, sino más bien una de las muchas influencias a considerar en el proceso de surgimiento y la determinación de las prerrogativas fundamentales. Palabras clave: Aparición de los derechos humanos; Vasak; Bobbio

\section{ABSTRACT}

The work entitled The Age of Rights, by Norberto Bobbio, is one of the main sources that affirm a first moment of protection in the historical of the constitutionalism that, in the line of the thought of Karel Vasak, determined the emergence of denominated civil and political rights as prerogatives of first generation or size. However, from the point of view of International Treaties and Conventions, the first protections did not occur with civil and political rights as proposed by Vasak and Bobbio, but rather by the social rights protected by the ILO (International Labor Organization) Convention 1919. Thus, deviations from the thinking of generations and dimensions of rights to the detriment of the first formalizations in International Treaties and Conventions end up punctuating problems that affirm that the emergence of human rights does not depend on the moment in which they were legally protected. The work concludes that the emergence of rights consists of a multifactorial process, reducing the positivist criterion that attentive to the historical moment of legal protection of rights as only one of several factors that must influence the emergence of these rights. In short, rights arise from innumerablefactors, including anthropological, historical, sociological, technological, and other factors; Placing the moment of legal protection and formalization of rights, not as a determining factor, but as one of the several influences to be considered in the process of emergence and determination of fundamental prerogatives.

Keywords: Emergence of human rights; Vasak; Bobbio

\section{SUMÁRIO}

INTRODUÇÃO.- I. DA DESCOBERTA DO CRITÉRIO REVISOR DO PENSAMENTO DAS GErações de direitos no pensamento de Karel Vasak e Norberto Bobbio.- II. DA CRISE DO CRITÉRIO JUSPOSITIVISTA NO PROCESO DE SURGIMENTO E DETERMINAÇÃO DE direitos e uma nova nomenclatura.-Considerações Finais.- Bibliografia. 
INTRODUÇÃO

O presente trabalho propõe rever sob o ponto de vista Dos Tratados e Convenções Internacionais, o famoso ideário das gerações (dimensões) de direitos desenvolvido pelos pensamentos de Karel Vasak e Norberto Bobbio sobre o processo de surgimento e determinação dos direitos humanos.

O pensamento das aclamadas gerações ou dimensões de direitos obteve expressiva repercussão pelo trabalho de Norberto Bobbio na obra intitulada $A$ era dos direitos ${ }^{1}$, que relatou a famosa aula magna e inaugural do Instituto de Direitos Humanos ministrada por Karel Vasak que, genuinamente, defendeu o processo de surgimento de direitos pelas três primeiras "gerações" (dimensões).

Trata-se de uma primeira geração (dimensão) de prerrogativas voltadas aos direitos civis e políticos, uma segunda geração de prerrogativas voltada aos direitos sociais e econômicos, e, por fim, uma terceira geração de direitos voltada aos direitos difusos e coletivos ligada à fraternidade e solidariedade.

Ocorre que, na perspectiva dos Tratados e Convenções Internacionais, os primeiros direitos humanos não foram os direitos civis e políticos, mas sim os direitos sociais com advento da Convenção da OIT (Organização Internacional do Trabalho) de 1919 e não com os direitos civis e políticos como defendeu Norberto Bobbio e Karel Vasak.

A problemática de descompasso entre o pensamento de Karel Vasak e Norberto Bobbio que defendiam a primeira "geração" ou "dimensão" de direitos para os direitos civis e políticos em detrimento aos primeiros momentos de proteção nos Tratados e Convenções Internacionais foi, justamente, o critério sobre o qual a proposta dos autores estava assentada. Tratava-se do surgimento de prerrogativas com base no momento do histórico do constitucionalismo em que galgaram a respectiva proteção.

1 Norberto Bobbio, A era dos direitos (Carlos Nelson Coutinho, trad., Elsevier, Rio de Janeiro, 2004). 
Trata-se, portanto, de um critério essencialmente positivista de verificar o surgimento de direito no momento em que eram protegidos juridicamente, de modo que vale uma passagem da obra intitulada A era dos direitos, de autoria de Bobbio, onde o autor irá assumir uma pontual divergência a outro trabalho intitulado Sobre a questão judaica, de Karl Marx².

Esta pontual divergência é muito pouco divulgada, porém se atenta a observação de que, enquanto Bobbio defendia a universalidade, Marx dizia que um dos documentos mais relevantes pertencente a primeira "geração" ou "dimensão" de direitos não referenciou o homem universal, mas sim o burguês.

Viabilizando, assim, afirmação de uma categoria subjetiva que teve efetivado seus direitos em detrimento a outros que ficaram excluídos, em que pese a universalidade meramente abstrata. Permitindo, desse modo, uma hipótese de pesquisa em que no surgimento de direitos há de ser vislumbrado não somente o momento de proteção jurídica no histórico do constitucionalismo, mas também outros fatores, no caso de Marx a efetividade real de direitos para uma determinada categoria de sujeitos, em detrimento aos demais. Assim, reduzindo a universalidade como mera abstração teórica marcada por significativa deformidade no campo da efetividade real que favorecia alguns em detrimento dos outros.

I. DA DESCOBERTA DO CRITÉRIO REVISOR DO PENSAMENTO DAS GERAÇÕES DE DIREITOS NO PENSAMENTo de Karel VAsAK E Norberto Bobbio

O pensamento das gerações (dimensões) de direitos é a vertente majoritariamente aceita na dogmática jurídica, inclusive, sob o efeito da constitucionalização dos diversos ramos do Direito, muitas doutrinas civilistas, penais, ambientais e de diversos segmentos da ciência jurídica aderiram a esta concepção, ense-

2 Karl Marx, Sobre a questão judaica (Nélio Schneider, trad., Boitempo, São Paulo, 2010). 
jando um pensamento bastante fortalecido e cuja projeção vale ser investigada.

A idealização do pensamento das gerações (dimensões) de direitos pertence a autoria de um jurista tchecoslovaco, naturalizado na França, chamado Karel Vasak que, em 1979, ministrou as primeiras ideias deste pensamento em uma Conferência no Instituto Internacional de Direitos Humanos de Estrasburgo (França).

Ocorre que no estudo das razões que, realmente, divulgaram o ideário geracional, encontramos uma obra literária sobre a qual, majoritariamente, recaem os verdadeiros motivos que levaram a repercussão hoje existente sobre esta temática, consistente no livro de um de seus principais defensores, Norberto Bobbio, intitulado $A$ era dos direitos.

O jurista brasileiro Paulo Bonavides foi o maior defensor deste pensamento no Brasil, inclusive acrescendo alguns adicionais no pensamento genuíno de Karel Vasak com o cúmulo de uma quarta e quinta geração (dimensão) de direitos no pensamento que, originariamente, era composta apenas de três gerações (dimensões) de direitos, correspondente as três terminologias do lema revolucionário francês de 1789: Liberté, Égalité, Fraternité (Révolution Française, 1789-1799).

Assim, têm-se os primeiros acréscimos geracionais no ideário genuíno que irá ser responsável pelos primeiros passos no distanciamento e na elevação do grau de abstração de uma construção que optou por restringir-se a analisar tão somente as textualizações e os documentos jurídicos responsáveis pelas positivações de prerrogativas.

O critério formal positivista que observa o surgimento de direitos no momento da respectiva positivação ou formalização durante o histórico do constitucionalismo, na verdade, consiste em um critério usado até de forma ideológica e pacificação social através de um modo simbólico de galgar a legitimidade quanto a própria ineficácia da lei, no caso, por exemplo, da Lei Seca dos Estados Unidos: 
A sua tese central afirma que os defensores da proibição de consumo de bebidas alcoólicas não estavam interessados na sua eficácia instrumental, mas sobretudo em adquirir maior respeito social, constituindo-se a legislação como símbolo de status. Nos conflitos entre protestantes nativos defensores da lei proibitiva e católicos imigrantes contrário à proibição, a 'vitória legislativa' teria funcionado simbolicamente a um só tempo como 'alto de deferência para os vitoriosos e de degradação para os perdedores, sendo irrelevantes os seus efeitos instrumentais ${ }^{3}$.

Assim como os textos constitucionais, também as suspeições de uma efetividade deformada com favorecimentos específicos declináveis somente para determinada categoria de sujeitos podem ser verificáveis na perspectiva dos excluídos. Aludindo ao lema francês setecentista que legitimou o constitucionalismo naquilo que Karel Vasak denominou de primeira geração ou dimensão de direitos:

Em 1789, quando os revolucionários franceses levantaram a bandeira tricolor simbolizando liberté, egalité, fraternité, em um dos maiores movimentos da história do Ocidente, ninguém poderia imaginar que 200 anos mais tarde a humanidade assistiria apaticamente à fome e à violência racial em vastas regiões da Africa, ao neonazismo, aos conflitos étnicos na Europa, ao massacre dos sem-terra no Brasil e tantos outros genocídios que o homem vem cometendo contra o próprio homem ${ }^{4}$.

Foi, justamente, esta deformidade que chamou a atenção da presente proposta e que se atentou para um pontual recorte do trabalho intitulado $A$ era dos direitos, principal divulgadora do pensamento das gerações ou dimensões de direitos. Trata-se de uma divergência do seu autor, Norberto Bobbio, em detrimento ao pensamento que repudiava a universalidade de um dos mais significativos documentos inserido no contexto da primeira geração ou dimensão de direitos no trabalho de Karl Marx denominado Sobre a questão judaica.

3 Marcelo Neves, A Constitucionalização simbólica, 176-177 (WMF Martins Fontes, São Paulo, 2007).

4 Patrícia Ramos Braick \& Myriam Becho Mota, História das cavernas ao terceiro milênio, 281 (Saraiva, São Paulo, 1999). 
Foi, justamente, na obra apontada com a principal responsável pela projeção deste pensamento de Karel Vasak e Norberto Bobbio que aprece uma pontual discordância entre o jurista italiano Norberto Bobbio (defensor da vertente geracional) divergindo do filósofo alemão KARL MARX:

[...] De nenhum modo se tratava do homem abstrato, universal! O homem de que falava a declaração era, na verdade, o burguês; os direitos tutelados pela Declaração eram direitos do burguês, do homem (explicava Marx) egoísta, do homem separado dos outros homens e da comunidade, do homem enquanto 'mônada isolada e fechada em si mesma' [...] A acusação feita por Marx à Declaração era a de ser inspirada numa concepção individualista da sociedade. A acusação era justíssima ${ }^{5}$.

Percebe-se que na obra que defende o pensamento geracional quanto aos direitos compreendidos como humanos e universais, há, também, o pensamento divergente de Karl Marx, afirmando que o documento não referenciava o homem universal, mas sim o burguês.

Trata-se de análise que se atenta ao campo da real efetividade de direitos universalmente protegidos, vislumbrando que, em que pese abstratamente universais, são direitos que foram protegidos para serem efetivos somente para alguns em detrimento dos demais.

Há, portanto, uma universalidade meramente abstrata, haja vista que não consegue transcender o campo da textualização, havendo nítida deformidade quando observada a realidade histórico e sociológico daquele momento em que direitos abstratamente universais foram protegidos para favorecerem somente alguns em detrimento dos outros.

Sendo do autor italiano, Bobbio, a autoria da obra que mais bem divulgou o pensamento das gerações (dimensões) de direitos e, justamente, a obra que possui o trecho desta pontual divergência em face ao filósofo alemão Marx que faz a primeira análise subjetiva do pensamento que bem depois seria defendido:

5 Norberto Bobbio, A era dos direitos, 46 (Carlos Nelson Coutinho, trad., Elsevier, Rio de Janeiro, 2004). 
A crítica oposta - segundo a qual a Declaração, em vez de ser demasiadamente abstrata, era tão concreta e historicamente determinada que, na verdade, não era defesa do homem em geral, que teria existido sem que o autor das Noites de São Petersburgo o soubesse, mas o burguês, que existia em carne e osso e lutava pela própria emancipação de classe contra a aristocracia, sem se preocupar muito com os direitos do que seria o chamado Quarto Estado - foi feita pelo jovem Marx no artigo sobre a "Questão Judaica", suficientemente conhecido para que não seja preciso nos ocuparmos de novo dele, e repetida depois, ritualmente, por diversas gerações marxistas ${ }^{6}$.

O filósofo alemão, portanto, apontou a referência ao homem burguês (levantando a perspectiva subjetiva). Porém, Bobbio, repudiou a crítica à Declaração, recuperando a referência do conteúdo ao homem em geral (ainda diante de uma carência real de uma universalidade efetiva ou de conteúdos positivados sem alcance efetivo).

A presente proposta irá afastar a abstração da universalidade desses conteúdos que inviabilizam a lucidez da perspectiva subjetiva e efetiva, de modo a adentrar nos questionamentos de quem e para quem eles ganharam as previsões que deram origem as diferentes gerações (dimensões) de direitos.

$\mathrm{O}$ enfoque adstrito as proteções de conteúdos jurídicos (aspecto positivista e formal) não é plenamente confiável, pois não cogitar os contextos que levaram a produção escrita, bem como os interesses e os reais titulares e destinatários dessas textualizações jurídicas que galgaram a dimensão das positivações, porém em países cujo bloqueio do sistema jurídico que se apresenta com valores sem concretização normativo e jurídica das textualidades constitucionais vale ressaltar a deformação dos textos constitucionais no processo de concretização que para ser evitado irá depender de um momento de ruptura, sobretudo, entre os agentes que protagonizam o poder político:

O Estado apresenta-se como identificado com os valores constitucionais, que não se realizam no presente por culpa do subdesenvolvimento da 'sociedade' [...] não se pode excluir a possibilidade, porém, de que a realização

6 Norberto Bobbio, A era dos direitos, 46 (Carlos Nelson Coutinho, trad., Elsevier, Rio de Janeiro, 2004). 
dos valores democráticos expressos no documento constitucional pressuponha um momento de ruptura com ordem de poder estabelecida, com implicações constitucionalmente contrárias à diferenciação e à identidadelautonomia do direito. Isso se torna tanto mais provável à proporção que os procedimentos previstos no texto constitucional sejam deformados no decorrer do processo de concretização e não de se operacionalizem como mecanismos estatais de legitimação ${ }^{7}$.

Vejamos, por exemplo, a Declaração de Independência dos Estados Unidos que foi preparada por um comitê de cinco membros, presidido por Thomas Jefferson (1743-1826). Inspiravam-se conteúdos de ideais iluministas, que defendiam a liberdade individual do cidadão e criticavam a tirania dos governantes ${ }^{8}$, porém o próprio Thomas Jefferson foi um dos grandes proprietários de escravos de seu tempo:

O direito à liberdade e à busca da felicidade que constava na Declaração de independência dos EUA não valia para todas as pessoas. A escravidão negra, por exemplo, foi plenamente mantida nos Estados Unidos até a Guerra da Secessão (1861-1865). Os autores da independência dos Estados Unidos não se preocuparam com mais de um milhão de negros que sofriam tortura, exploração e humilhação do trabalho escravo. Aliás o próprio Thomas Jefferson foi um dos grandes proprietários de escravos de seu tempo, embora fosse, teoricamente, antiescravista e abolicionista $[\ldots]^{9}$.

Os índios americanos também estavam submetidos às mesmas sujeições, ainda que ocorressem os avanços dos documentos de expressão de valores de liberdade e felicidade:

[...] Os índios americanos também não tiveram o mesmo direito à liberdade e à felicidade garantidas aos proprietários burgueses. Durante todo o período colonial e depois da independência, recebeu dos brancos o massacre de suas tribos, a destruição de sua cultura e a expulsão de suas terras. Até mesmo as mulheres americanas não desfrutavam os mesmos direitos civis reservados aos homens. Naquela época, a mulher era considerada um ser

7 Marcelo Neves, A Constitucionalização simbólica, 176-177 (WMF Martins Fontes, São Paulo, 2007)

8 Jaime Rodrigues \& Gilberto Cotrim, Saber e fazer história: consolidação do capitalismo e Brasil Império, V. 3, 45 (8 ed., Saraiva, São Paulo, 1999).

9 Jaime Rodrigues \& Gilberto Cotrim, Saber e fazer história: consolidação do capitalismo e Brasil Império, V. 3, 44 (8 ed., Saraiva, São Paulo, 1999). 
inferior e, por isso, permaneceu subordinada ao poder absoluto do homem. Quem, então, exercia plenamente os direitos de cidadão, assegurados na constituição americana de 1787? Em linhas gerais, a plena cidadania foi exercida pela poderosa burguesia industrial e comercial do Centro-Norte e pelos donos de fazenda do Sul [... $]^{10}$.

O presente trabalho vai aproveitar a crítica contrária ao pensamento geracional em dois principais pontos de falhas desta vertente; em razão, justamente, deste apego cego ao conteúdo que está se positivando em face desta omissão insistente em não questionar os reais titulares e destinatários dessas positivações (aspecto subjetivo).

Quando um pensamento impõe uma ordem de previsões de prerrogativas (conteúdos em sequência de previsões), abre-se margem para conferência desta ordem sequencial de previsão em documentos jurídicos de natureza diversa, como uma forma de conferir a uniformidade lógica da proposta teórica.

Ocorre que em uma investigação mais profunda acerca da temática, verifica-se que a ordem sequencial de conteúdos referentes, primeiramente, a matérias atinentes a direitos civis e políticos (primeira geração), depois matérias relativas a direitos sociais (segunda geração), não se verifica quando se vislumbra a ordem sequencial de previsão de conteúdos em documentos jurídicos diversos dos textos constitucionais, por exemplo, provenientes de Tratados e Convenções Internacionais.

Do ponto de vista dos Tratados e Convenções Internacionais os primeiros direitos protegendo seres humanos no plano internacional foram as Convenções da OIT (Organização Internacional do Trabalho) de 1919, em suma, prerrogativas relativas ao trabalho (direitos sociais) e os direitos civis e políticos (pertencentes à primeira geração) só foram previstos no âmbito dos Tratados e Convenções Internacionais em 1966 (Pacto de Direitos Civis e Políticos), ou seja, muito tempo depois das Convenções do Trabalho de 1919.

10 Jaime Rodrigues \& Gilberto Cotrim, Saber e fazer história: consolidação do capitalismo e Brasil Império, V. 3, 44 (8 ed., Saraiva, São Paulo, 1999). 
Nesse sentido uma crítica contrária a vertente geracional construída por, no geral, juristas internacionalistas que reiteram seus argumentos, dentre os quais, Flávia Cristina Piovesan, Antônio Augusto Cançado-Trindade, Jairo Schäfer, Carlos Weis e até Valerio Mazzuoli que é categórico quando diz:

[...] a consagração nas Constituições dos direitos sociais foi, em geral, posterior à dos direitos civis e políticos, ao passo que no plano internacional o surgimento da Organização Internacional do Trabalho, em 1919, propiciou a elaboração de diversas convenções regulamentando os direitos sociais dos trabalhadores, antes mesmo da internacionalização dos direitos civis e políticos no plano externo ${ }^{11}$.

A descoberta do presente trabalho resolve a problemática investigativa inaugural, pois a razão da doutrina geracional não se conferir quando vislumbrada do ponto de vista dos Tratados e Convenções Internacionais corresponde, justamente, no critério em que as gerações (dimensões) de direitos se desenvolveram desde Karel Vasak, ou seja, estritamente nos conteúdos que ganharam essas previsões e positivações jurídicas.

Portanto, o descompasso existente entre a evolução das diferentes dimensões e gerações dos direitos na perspectiva da natureza constitucional em detrimento aos textos e positivações de natureza diversas, tal como, a verificação nos Tratados e Convenções Internacionais foram o ponto que levaram o aprofundamento da presente suspeição e que orientaram o reconhecimento de um vício de análise teórica, onde a produção e construção do Direito não deve analisar tão somente a perspectiva do conteúdo que está ganhando as previsões no decorrer dos diferentes momentos históricos, mas também outros planos de averiguação.

Logicamente que uma doutrina desenvolvida com base apenas em determinar direitos fundamentais considerando o momento em que tais direitos foram protegidos gicam vulneráveis quando os conteúdos de uma abordagem diversa não coincidir; por isso é que as investigações apontaram por uma constante

11 Valerio de Oliveira Mazzuoli, Curso de direito internacional público, 858 (7 ed., Editora Revista dos Tribunais, São Paulo, 2013). 
apta para rever o ideário geracional correspondente à figura do sujeito de direitos, ou melhor, da subjetividade jurídica (titulares desses conteúdos e reais beneficiários).

Fica bastante claro que direitos fundamentais não nascem somente no momento ou contexto político de sua respectiva proteção, de modo que a formalização desses direitos é apenas um aspecto positivista de sua determinação e surgimento, haja vista que direitos fundamentais nascem de inúmeros fatores, dentre os quais, de ordem histórica, sociológica, política, antropológica, tecnológica e outras influências, sendo o momento de sua proteção apenas uma das influências a ser considerada.

$\mathrm{O}$ segundo ponto que a presente proposta reaproveita corresponde a uma famosa corrigenda terminológica que evolui a nomenclatura "gerações" para "dimensões".

Esta corrigenda de nomenclaturas evoluiu a expressão "gerações" para "dimensões" pautando-se em um erro que, de fato, merece ser corrigido, pois indicou com uma expressão terminológica cujo significado possui um sentido sucessório, em suma, de encerramento de uma fase em detrimento de outra (fenômeno que, de fato, não ocorre); pois o encerramento de um momento de previsão de prerrogativas (primeiras gerações) não encerram as prerrogativas do contexto subsequente (segunda geração), ou seja, não há sucessão ou substituição dos direitos de uma fase pela outra, mas acréscimos dos conteúdos que avançaram nas respectivas previsões jurídicas.

Em outras palavras, a evolução de nomenclaturas corrigidas pelos próprios defensores da vertente geracional possui sua principal razão na ideia acertada de que o significado da expressão geração leva implicitamente um sentido sucessório, ou seja, de uma geração suceder ou substituir a outra e, de fato, não é isso que ocorre.

Os conteúdos e prerrogativas de um momento não se encerram para o nascimento de outros direitos e conteúdos, de modo que os diferentes momentos cumulam entre si os diferentes direitos que galgaram as respectivas positivações, por isso, que a 
proposta acertada pela evolução terminológica "geração" para "dimensão" de direitos.

E, nesse contexto, indaga-se: qual seria o elemento que orientaria a proposta, desde a sua origem, de modo a vislumbrar o aspecto cumulativo e não o sucessório?

Uma reflexão sobre considerar, desde a elaboração do pensamento das gerações, o enfoque subjetivo (titularidade e subjetividade jurídica) e não os objetos das positivações, daria ao seu autor, na origem do pensamento, maior chances de acertar a terminologia, pois considerar a perspectiva subjetiva (titularidade) seria o mesmo que afirmar o sujeito ou o titular sobre o qual todo o conteúdo ou todas as prerrogativas seriam cumuladas (afastando a ideia de sucessão), ou seja, considerar a perspectiva subjetiva concentraria as prerrogativas das diferentes gerações em uma mesma titularidade (aspecto subjetivo), aumentando as chances de prevenir o pensamento da corrigenda que se sujeitou.

Portanto, dois pontuais erros que valem ser enfatizados como forma de demonstrar o risco de construções teóricas que confiem cega e exclusivamente em apenas um ponto de observação, no caso, baseados essencialmente nos conteúdos previstos (aspecto formal objetivo), sem o questionamento acerca dos titulares e reais destinatários dessas previsões (aspecto subjetivo).

O ponto em que Norberto Bobbio irá fazer resistência e contraposição a afirmação do filósofo alemão Karl Marx foi, precisamente, o ponto que aprofundamento que deflagra a solução dos dois grandes vícios trazidos pela corrente desfavorável ${ }^{12}$.

II. DA CRISE DO CRITÉRIO JUSPOSITIVISTA NO PROCESSO DE SURGIMENTO E DETERMINAÇÃO DE DIREITOS E UMA NOVA NOMENCLATURA

O desvio revelado no pensamento de Karel Vasak e Norberto Bobbio fica bastante destacado quando conferido do ponto de

12 Norberto Bobbio, A era dos direitos, 46 (Carlos Nelson Coutinho, trad., Elsevier, Rio de Janeiro, 2004). 
vista dos Tratados e Convenções Internacionais que começaram seu âmbito de proteção com os direitos sociais e não com os direitos civis e políticos como pretendeu a proposta geracional.

Assim, quando a proposta cronológica da sequência de uma primeira geração ou dimensão devota aos direitos civis e políticos é conferido no âmbito de proteção ocorrido em documentos de natureza diversa, tais como Tratados e Convenções, é que fica bastante manifesto o critério sobre o qual se assentou o ideário das gerações e dimensões de direitos, correspondente, justamente, no momento em que direitos foram protegidos no histórico do constitucionalismo (critério meramente formal).

A divergência entre Norberto Bobbio na obra intitulada $A$ era dos direitos em detrimento a Karl Marx no trabalho intitulado Sobre a questão judaica ajuda a perceber uma distinção bastante marcante que direitos universais podem ser positivados em um dado contexto histórico para serem efetivos somente para certas categorias de sujeitos.

Há, portanto, uma relação entre o momento de positivação e formalização histórica de prerrogativas e fatores políticos que demonstram manifestos interesses pode detrás de um contexto de proteção de direitos que não foram considerados pelo ideário de Vasak e de Bobbio como se outros fatores além tão somente do momento de positivação de direitos não importassem.

Um dado bastante relevante e que ajuda a confirmar que o surgimento real e efetivo de direitos e não tão somente no papel e em textualizações jurídicas merecem o relato do fenômeno estudado pelos autores da tutela coletiva, denominado Free riding. Pois os direitos difusos quando foram textualizados juridicamente, não iriam surgir e existir na realidade fática não fosse a implementação da proteção dos direitos difusos pertencentes à aclamada terceira geração de direitos.

Na terceira geração ou dimensão de direitos foram textualizados e formalizados pela primeira vez os direitos compreendidos como coletivos, especificamente os direitos difusos que ficariam paralisados tão somente nos textos da lei e não surgiriam na realidade fática. 
$\mathrm{O}$ fenõmeno Free riding, inerente da tutela coletiva designa uma tendência natural desses direitos consistente na imobilização ou neutralização de seus titulares, pois direitos difusos, tal como, ar atmosférico, patrimônio da humanidade, meio ambiente não possuem titulares determinados.

Os direitos difusos possuem essa peculiaridade de serem de todos e de responsabilidade de toda humanidade em sua proteção, portanto quando eles surgiram no âmbito das textualizações jurídicas; não haviam agentes específicos responsáveis pela sua efetivação. De modo que todos teriam que proteger direitos difusos e o problema de um bem ou valor pertencer a todos de uma só vez está na delegação, uma vez que ninguém vai deixar de fazer o que precisa fazer em seu dia para proteger algo que não pertence só a ele, mas a todos conjuntamente, gerando uma paralisia coletiva e, inclusive, reconhecida pelos estudos de direitos coletivos cuja o nome consiste em: Free Riding.

Reitera-se, assim, o meio ambiente acaba transferindo a responsabilidade para o outro que também é titular e responsável pela conservação e isso provoca uma determinada imobilização ou neutralização de todos em consequência de nenhum, em suma, o efeito carona que é indicado com esta expressão free riding:

Isto acaba por justificar a construção de um modelo de processo coletiva em que o sistema eleja representantes da coletividade para atuar em favor dos titulares indeterminados dos direitos ou interesses, neutralizando ou, ao menos, mitigando esta tendência natural à imobilização deles por conta de efeito carona da atuação alheia (free riding). Há, portanto, um impulso natural à imobilização dos agentes na defesa dos bens coletivos ${ }^{13}$.

No estudo dos conteúdos decorrentes da terceira geração (dimensão), um fenômeno intitulado free riding chama bastante a atenção, pois nas tutelas jurídicas usadas para proteger direitos que, originariamente, surgiram na terceira geração, dentre os quais, os direitos difusos ganham problemas sobre a falta "de

13 Fernando da Fonseca Gajardoni, Direitos difusos e coletivos I: teoria geral do processo coletivo, 17 (Saberes do Direito, 34, Saraiva, São Paulo, 2012). 
quem" (aspecto subjetivo) iria proteger conteúdos difusos de titularidade e sujeitos indeterminados.

Bens que pertencem a todos e na análise investigativa referenciam todos, perdem a especificação de categorias representativas, em suma, não há uma classe que os representem, de modo que a legitimidade de proteção acaba sendo atribuídas a entidades públicas e, por isso, compreende-se, pelo menos em medida, a ascensão do Ministério Público com a Constituição de 1988.

Existe um brocardo muito famoso que diz que aquilo que é de todos acaba não sendo de ninguém, tal como, o ar que é um bem difuso ou indeterminadamente de todos, de modo que não há uma categoria específica para representá-lo e tal conclusivo consiste, justamente, na mudança em optar por positivar conteúdos que não referencie categorias algumas, mas definitivamente todos, por isso que o Estado precisou suprir a falta que acabou sendo assumida, no geral, pelo Ministério Público.

A titularidade da terceira geração (dimensão) de direitos, no caso dos direitos compreendidos como difusos, há uma titularidade indeterminada que acaba sendo positivada e formalizada com a necessidade de terem legitimados que pudessem defender, prevenindo, assim, o surgimento meramente formal e não efetivo. Enfatizando, assim, que o surgimento de direitos não depende exclusivamente da formalização de prerrogativas, mas sim de um conjunto de fatores concomitantes a serem considerados.

Por isso que no estudo dos direitos difusos e coletivos, inclusive aqueles que mereceram as previsões jurídicas, atenta-se a um fenômeno bastante recorrente em sua doutrina, trata-se do chamado free riding, ou seja, formalizou-se direitos cuja a existência real e efetiva dependeu de legitimar instituições que pudessem defender e buscar a sua efetividade para que sua existência não fossem meramente formal, justamente, porque sua titularidade era indeterminada, exigindo do Estado não só a positivação de direitos para que estes surgissem, mas a determinação de representatividades que o efetivassem: "[...] Primeiro, a representação 
em juízo de interesses supraindividuais é fundamental para a tutela de direitos cuja titularidade é indeterminada"14.

Assim, fica claro que o descompasso existente entre a cronologia de proteção ocorrida na proposta de Karel Vasak e Norberto Bobbio que começou com os direitos civis e políticos, depois com a proteção dos direitos sociais. Não correspondendo, assim, com a proteção dos mesmos direitos, porém, ocorrida em documentos de natureza diversa, tal como nos Tratados e Convenções Internacionais que protegeram primeiramente os direitos sociais (com advento da Convenção da OIT - Organização Internacional do Trabalho de 1919).

O surgimento dos direitos, portanto, não pode se pauta única e exclusivamente no momento em que a prerrogativa é positivada, pois esta hipótese abre margem para conferência em outras positivações de natureza diversas, tornando-se um critério significativamente vulnerável.

$\mathrm{O}$ fator de momento em que direitos são positivados merece relevância não na qualidade de única e absoluta influência, mas na qualidade de uma das várias influências a serem analisadas conjuntamente com outra das mais diversas naturezas, dentre as quais, de ordem antropológica, sociológica, histórica, política, tecnológica e outras analisadas conjuntamente.

O surgimento dos direitos difusos na terceira geração ou dimensão pode ser um exemplo, haja vista que a simples positivação dessas prerrogativas difusas não foram suficientes para o surgimento real e efetivo desses direitos, uma vez que a simples proteção jurídica de direitos difusos, por exemplo, meio ambiente, patrimônio histórico da humanidade, recursos hídricos ou ar atmosférico não garante sua existência e surgimento real e efetiva, de modo que para garantir a proteção efetiva foi preciso que, concomitantemente, com a formalização dessas prerrogativas, legitimassem instituições que pudessem dar a existência

14 Fernando da Fonseca Gajardoni, Direitos difusos e coletivos I: teoria geral do processo coletivo, 17 (Saberes do Direito, 34, Saraiva, São Paulo, 2012). 
real e efetiva desses direitos quando ninguém a defendessem, evitando o fenômeno Free Riding (efeito carona).

No próprio trabalho que mais projetou o pensamento das gerações ou dimensões de direitos, denominado $A$ era dos direitos, aonde se observa a afirmação marxista de que um dos mais relevantes documentos inseridos na primeira geração de direitos não referenciou o homem universal, mas sim o burguês. Enfatizando, assim, uma existência efetiva de direitos que leva em consideração interesses e outros fatores que não tão somente a formalização de direitos, inserindo na discussão outras influências no processo de surgimento e afirmação de prerrogativas.

Portanto, direitos humanos surgiram e foram determinados não somente a partir do momento em que galgaram a respectiva positivação e proteção, sendo este critério (formal positivista) não mais um fator absoluta e determinante neste processo, mas sim mera influência que deve ser analisada conjuntamente com outras influências no processo de afirmação dos direitos humanos, inclusive influências das mais diversas naturezas, como antropológica, histórica, sociológica, tecnológica e outras. 


\section{CONSIDERAÇÕES FINAIS}

Destarte, quando a proposta geracional (dimensional) é tratada do ponto de vista dos Tratados e Convenções Internacionais, percebe-se o descompasso do pensamento de Karel Vasak e Norberto Bobbio acerca de quando direitos humanos foram determinados. Haja vista que os primeiros direitos da pessoa humana protegida internacionalmente foram os direitos sociais com advento da Convenção da OIT (Organização Internacional do Trabalho) de 1919 e não com os direitos civis e políticos como pretendeu a proposta de Bobbio e Vasak.

Esses desvios ocorreram, justamente, por razões do critério que foi adotado, pautado em um fator positivista formal de afirmar prerrogativas na medida em que eram juridicamente previstas no decorrer do histórico do constitucionalismo, abrindo margem para a conferência da proteção dos mesmos direitos no bojo de documentos jurídicos de natureza diversa, tal como nos Tratados e Convenções Internacionais.

A divergência assumida por Norberto Bobbio na obra intitulada $A$ era dos direitos em detrimento ao trabalho denominado Sobre a questão judaica de Karl Marx ajuda a concluir que o momento de previsão constitucional não é o único fator a ser considerado no processo de surgimento dos direitos. Percebendo que direitos humanos universais foram protegidos na Revolução Francesa de 1789, porém foram efetivados somente para alguns, no caso os burgueses que lograram neste episódio do constitucionalismo.

Por isso que Marx repudiou a universalidade divergida por Bobbio, dizendo que um dos principais documentos inseridos na primeira geração ou dimensão de direitos não referenciava homem universal, mas o burguês, aludindo, justamente, outro fator (real efetividade) que não a abstração positivista da universalidade.

Pode-se concluir que o processo de surgimento e determinação dos direitos não consiste em um processo que deve considerar única e exclusivamente o momento de proteção jurídica 
como fator determinante no respectivo surgimento, mas outros fatores de ordem sociológica, antropológica, tecnológica e etc.

O pensamento de Karel Vasak e Norberto Bobbio defendeu o surgimento de prerrogativas a partir de fases de proteção denominadas gerações ou dimensões de direitos; porém, não sendo o critério formal positivista o único fator neste processo, admitese a análise subjetiva feita por Marx que enfatiza para quem os direitos abstratamente universais foram efetivados na realidade sociológica, inclusive, propondo uma terceira terminologia (depois das gerações ou dimensões de direitos), tratando-se das: sujeições aos direitos (alusão de quem deve sujeitar no campo da real efetividade com a respectiva proteção jurídica).

Reduzindo, assim, o critério formal positivista que vislumbra o momento e contex to histórico de proteção jurídica de direitos não como um fator determinante, mas sim como uma das várias influências no processo de determinação e surgimento dos direitos, devendo ser analisados com outros das mais diversas ordens, dentre as quais, antropológica, sociológica, tecnológica, psicológica e outras.

Por isso, a proposta de uma terceira evolução terminológica na nomenclatura que, originariamente, foi intitulada gerações de direitos por Karel Vasak e, posteriormente, evoluiu para $d i$ mensões de direitos por diversas vertentes constitucionalistas e, agora e por fim, o trabalho buscou a proposta de uma terceira intitulação: sujeições de direitos. 


\section{BIBLIOGRAFIA}

\section{Livros}

Bobbio, Norberto, A era dos direitos (Carlos Nelson Coutinho, trad., Elsevier, Rio de Janeiro, 2004).

Braick, Patrícia Ramos \& Mota, Myriam Becho, História das cavernas ao terceiro milênio (Saraiva, São Paulo, 1999).

Gajardoni, Fernando da Fonseca, Direitos difusos e coletivos I: teoria geral do processo coletivo (Saberes do Direito, 34, Saraiva, São Paulo, 2012).

Marx, Karl, Sobre a questão judaica (Nélio Schneider, trad., Boitempo, São Paulo, 2010).

Mazzuoli, Valerio de Oliveira, Curso de direito internacional público (7 ed., Editora Revista dos Tribunais, São Paulo, 2013).

Neves, Marcelo, A Constitucionalização simbólica (São Paulo: WMF Martins Fontes, 2007).

Rodrigues, Jaime \& Cotrim, Gilberto, Saber e fazer História: consolidação do capitalismo e Brasil Império, V. 3 (8 ed., Saraiva, São Paulo, 1999). 